\title{
An Augmented Y-Spray System to Visualize Biological Effects for Human Body
}

\author{
Seiya Manabe ${ }^{1, *}$, Hideki Tenzou ${ }^{2}$, Takaaki Kasuga ${ }^{1}$, Yukiko Iwakura ${ }^{1}$ and Robert Johnston ${ }^{2}$ \\ ${ }^{1}$ National Institute of Technology, Kagawa College, Advanced Course in Electronics, Information and Communication Engineering, \\ Electronic Systems Course, 551 Kohda, Takuma-cho, Mitoyo-shi, Kagawa, 769-1192, Japan \\ ${ }^{2}$ National Institute of Technology, Kagawa College, Department of Electronic Systems Engineering, 551 Kohda, Takuma-cho, Mitoyo- \\ shi, Kagawa, 769-1192, Japan
}

\begin{abstract}
The purpose of this study was to develop a new educational system with an easy-to-use interface in order to support comprehension of the biological effects of radiation on the human body within a short period of time. A paint spray-gun was used as a gamma rays source mock-up for the system. The application screen shows the figure of a human body for radiation deposition using the $\gamma$-Sprayer, a virtual radiation source, as well as equivalent dosage and a panel for setting the irradiation conditions. While the learner stands in front of the PC monitor, the virtual radiation source is used to deposit radiation on the graphic of the human body that is displayed. Tissue damage is calculated using an interpolation method from the data calculated by the PHITS simulation code in advance while the learner is pulling the trigger with respect to the irradiation time, incident position, and distance from the screen. It was confirmed that the damage was well represented by the interpolation method. The augmented $\gamma$-Spray system was assessed by questionnaire. Pre-post questionnaire was taken for our 41 students in National Institute of Technology, Kagawa College. It was also confirmed that the system has a capability of teaching the basic radiation protection concept, quantitative feeling of the radiation dose, and the biological effects
\end{abstract}

\section{Introduction}

After the accident at Tokyo Electric Power Company's (TEPCO) Fukushima Dai-Ichi Nuclear Power Plant, not only specialists in radiation but also a lot of people in general have a growing interest in radiation protection. It's important to learn how to protect yourself from radiation through quantitative discussions for the safe use of radiation or decontamination work aimed at reducing radiation levels. Some handbooks and eLearning tools have been prepared for use in schools for relatively-long courses to teach deterministic effects and probabilistic effects with the units themselves. Some learners, however, often get confused between the absorbed dose D [Gy] and the effective dose H [Sv]. It's difficult for the lay public to understand both the physical definitions and the calculation methods of each intuitively [1]. Therefore, the purpose of this study was to develop a new short interactive educational demo system with an easy-to-use interface to support comprehension of the biological effects that radiation can have on the human body.

\section{System overview}

Figure 2 shows an overview of the new system. It has a spray-type user interface. The learner stands in front of a PC monitor and aims the virtual $\gamma$-Sprayer at the monitor where an image of the human body is displayed. The time elapsed pulling the trigger is proportional to the total number of virtual $\gamma$-rays emitted from the nozzle. The position and orientation of the gun is tracked by a "Leap Motion" non-contact sensor. Irradiation points are calculated from the sensor data. The learner can control the irradiated centre position by handling the $\gamma$-Sprayer and can focus on the centre by changing the distance from the monitor. The learners can intuitively understand that there are three ways to protect themselves from radiation. One of them is to keep your distance from radioactive materials. The second point is to reduce the exposed time to radiation. The learners can observe the change of effective dose depending on irradiation

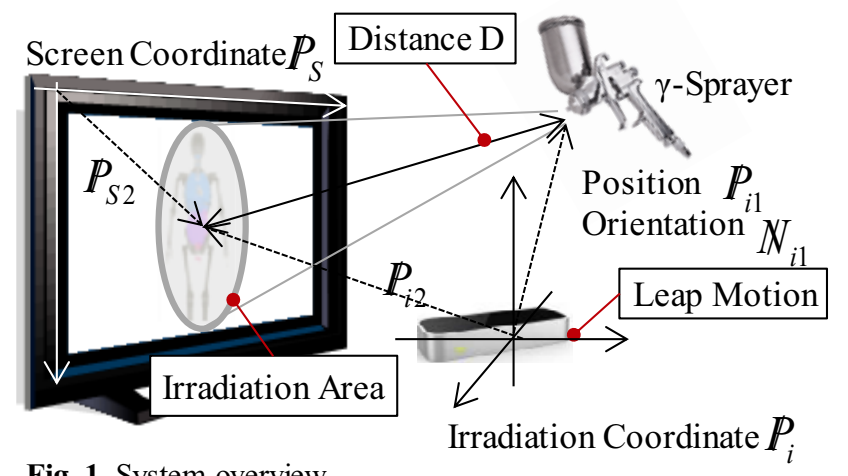

Fig. 1. System overview.

\footnotetext{
* Corresponding author: manabe@araes.kyushu-u.ac.jp
} 
positions. Thus, the third point is to understand which or gans or tissues have higher radiation sensitivity. The radioactivity is selectable through the GUI.

The educational system was developed on a 64-bit Windows 8 platform in the Processing programming language. The PC was equipped with an Intel Core i7$4820 \mathrm{~K}(3.70 \mathrm{GHz}), 16 \mathrm{~GB}$ of RAM and a NVIDIA GeForce GTX 770 graphic card.

\subsection{Data flow diagram}

Figure 2 shows the data flow diagram of the system. The educational system is required to display the radiation biological effects and effective dose in real-time. The system was designed to estimate the dose rate for any incident position on the human body by using an interpolation approximation to save time calculating radiation damage. The PHITS (Particle and Heavy Ion Transport code System) Ver. 2.70 simulation code [2] was used to calculate the dose data per number of incident $\gamma$-rays hitting the organs and tissue for each incident position at $10 \mathrm{~cm}$ intervals. The dose data for each incident position on the human body for the precalculations was called the "Response functions". The MIRD (Medical Internal Radiation Dose) phantom [3] was used as the physical model of the human body.

The "Leap Motion" non-contact sensor acquires the position of the virtual $\gamma$-Sprayer. Irradiation points on the monitor are calculated from the position and orientation of the $\gamma$-Sprayer. The effective dose and equivalent dose of organs and tissues are calculated by multiplying the interpolation values based on response functions of both the duration the trigger is engaged and the pressure applied to the trigger.

The damage for each organ in the human body is rendered at an interval of 0.5 seconds. Learners can see the effects that the radiation has on each organ in the textboxes on the monitor in real time.

\subsection{Mechanical System}

\subsubsection{Tracking}

A Leap Motion sensor was used to track the position and orientation of the $\gamma$-Sprayer. The gesture sensor has a view field of approximately $150^{\circ}$ and uses a depth sensor to track hand features down to 1/100th of a millimetre. The Leap Motion works with two infrared (IR) cameras and three IR LEDs as a depth sensor in a limited field of approximately 61 cubic centimetres. Using the stereoscopy provided by using both cameras, the device can minimize position errors of the $\gamma$-Sprayer. The sensor was set on the same stage as the monitor. The relative position $P_{0}\left(x_{0}, y_{0}\right)$ between the sensor and the monitor must be calibrated at start-up. The $\gamma$-Sprayer is identified through acquiring the shape of the nozzle parts by using the Leap Motion V2 Beta Software Development Kit (SDK).

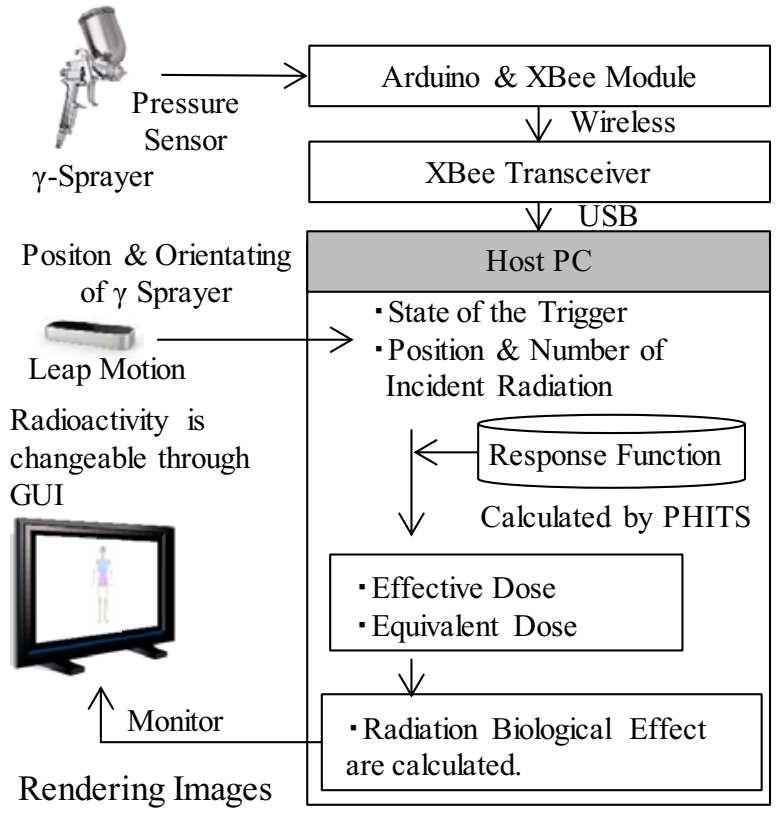

Fig. 2. Data flow diagram.

\subsection{2 y-Sprayer Controller}

Figure 3 is a structure of $\gamma$-Sprayer. EARTH MAN Takagi suction-feed spray gun was manufactured by Takagi CORPORATION and remodelled to $\gamma$-Sprayer Controller. A pressure sensor was attached to the trigger to measure the position of the trigger. The data is sent while the trigger is pulled. The analogue data is converted to digital data by an Arduino Uno R3 and the digital data is sent via an "XBee" wireless module to the main program on a host $\mathrm{PC}$. In the main program, the emission number (intensity) $N$ of the $\gamma$-rays is calculated by the following equation (1).

$$
N=N_{0} \cdot d T_{\text {trig }} \cdot F_{\text {trig }}
$$

Where, $N_{0}$ is a constant value and $d T_{\text {trig }}$ is the elapsed time of the trigger at the trigger pressure force $F_{\text {trig. The }}$ spray spreads out $\gamma$-rays in a solid angle determined by $2 \pi\left(1-\cos 5^{\circ}\right)$.

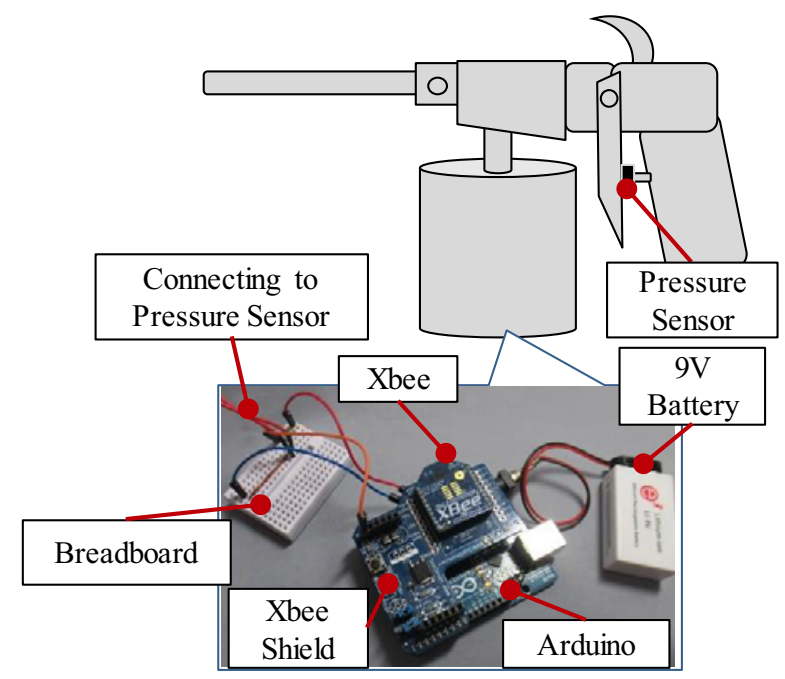

Fig. 3. Structure of $\gamma$-Sprayer controller. 


\subsection{Physical model}

\subsubsection{Response Functions calculated by PHITS}

Response functions were calculated by using the PHITS Monte Carlo simulation code and a MIRD mathematical human phantom placed in a vacuum. PHITS can simulate the transport of all particles such as nucleons, nuclei, mesons, photons, and electrons in arbitrary geometries composed of any element, compound or mixture. The phantom is a heterogeneous mathematical representation of the human body to estimate absorbed doses from internal and external exposure. In order to estimate an accurate effective dose, it was necessary to distinguish the absorbed dose in the red bone marrow from that of the bone surface. Both of them are, however, defined as one material, "Bone", in the MIRD phantom. Therefore, the absorbed dose of "Bone" was divided into that of the red bone marrow and that of the bone surface according to their masses.

The height and weight of the phantom body is based on the national mean Japanese male at $174 \mathrm{~cm}$ and $73 \mathrm{~kg}$ respectively. Table 1 shows the elemental compositions and densities of each organ and tissue for the MIRD phantom model. 1.0 MeV $\gamma$-rays from Co60 were selected as the incident radiation for this system. Response functions for each incident position and angle were calculated at a $10 \mathrm{~cm}$ interval. The irradiation system in this system is showed in Figure 4. Response functions have relationship between irradiation position on human body $(x, y)$, distance from human body to radiation source $L$, horizontal angle $\varphi$ and vertical angle $\theta$. The parameter $L$ was set from $200 \mathrm{~cm}$ to $700 \mathrm{~cm}$ by $100 \mathrm{~cm}$. The $\varphi$ or $\theta$ was set from $0^{\circ}$ to $180^{\circ}$ by $30^{\circ}$. Response functions are saved as text files in a direct folder of the running program. Absorbed dose is

Table 1. Elemental compositions and densities in each organs and tissue for the MIRD phantom model.

\begin{tabular}{|c|c|c|c|c|c|c|c|c|c|c|c|}
\hline Organ & $\begin{array}{c}\text { Density } \\
{\left[\mathbf{g}^{\mathbf{c} \mathbf{c m}^{\mathbf{3}} \text { ] }}\right.}\end{array}$ & $\mathbf{H}$ & $\mathbf{C}$ & $\mathbf{N}$ & $\mathbf{O}$ & $\mathbf{C a}$ & $\mathbf{N a}$ & $\mathbf{P}$ & $\mathbf{S}$ & $\mathbf{C l}$ & $\mathbf{K}$ \\
\hline Lung & 0.30 & 10 & 10 & 2.9 & 76 & - & 0.2 & 0.1 & 0.2 & 0.3 & 0.2 \\
\hline Bone & 1.49 & 7.3 & 26 & 3.1 & 48 & 10 & 0.3 & 5.1 & 0.2 & 0.1 & 0.1 \\
\hline $\begin{array}{c}\text { Soft } \\
\text { Tissue }\end{array}$ & 0.99 & 11 & 23 & 2.5 & 64 & - & 0.1 & 0.1 & 0.2 & 0.1 & 0.2 \\
\hline
\end{tabular}

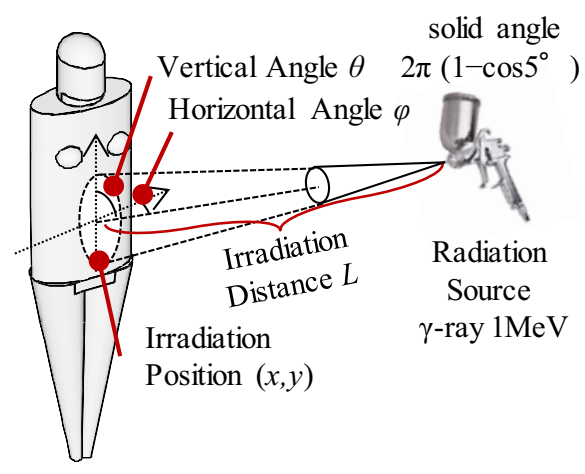

MIRD Phantom

Fig. 4. The target of human body is being irradiated by using spray-type interface. estimated by using interpolation method in real time.

\section{2) Radiation Dose Estimation Method}

Equivalent dose $H_{\mathrm{T}}$ is calculated by the following equation (2) to determine the biological effects of the radiation.

$$
H_{\mathrm{T}}=\Sigma_{\mathrm{R}} W_{\mathrm{R}} \cdot D_{\mathrm{T}, \mathrm{R}}
$$

Where, $D_{\mathrm{T}, \mathrm{R}}$ is the absorbed dose deposited in an organ or tissue T by radiation $\mathrm{R}$, and $W_{\mathrm{R}}$ is the radiation weighting factor. $W_{\mathrm{R}}$ is dependent on the type and energy of radiation R. Our current system selects $\gamma$-rays as the incident radiation. The radiation weighting factor $W_{\mathrm{R}}$ is ' 1 '.

Effective dose $E$ is calculated by the following equation (3).

$$
E=\Sigma_{\mathrm{T}} W_{\mathrm{T}} \cdot H_{\mathrm{T}}
$$

Where, $W_{\mathrm{T}}$ is the tissue weighting factor defined by regulation as showed in Table 2. $E$ is the tissue-weighted sum of the equivalent doses in all specified organs and tissues. The $W_{\mathrm{T}}$ is referred to the ICRP Publication 60 [4]. The $E$ represents the stochastic health risk, which the probability of cancer induction and genetic effects of ionizing radiation delivered to those body parts.

Each damage or symptom for human body is estimated based on the absorbed doses, the equivalent doses or the effective doses given by above equation (2) and (3). Deterministic effects considered in this system are listed in Table 3. Deterministic effects have thresholds below which the effects do not occur. The threshold for each symptom is also listed in Table 3. The symptoms for each of the organs or tissues were calculated based on the values of the absorbed doses or the effective doses in real time. Probabilistic effects considered in this system are fatality cancer incidences in each parts of human body. Fatality cancer incidences are propositional to equivalent doses of each part. Fatality probability coefficients in each part are also refed to ICRP Pub. 60 and listed in Table 4. The irradiated effective dose is compared with the general exposure. Considered general exposures are listed in Table 5.

Table 2. Tissue weighting factor for each organs and tissue.

\begin{tabular}{|c|c|}
\hline Organ or Tiss ue & Tissue Weighting Factor \\
\hline Gonands & 0.20 \\
\hline Bone Marrow (Red) & 0.12 \\
\hline Colon & 0.12 \\
\hline Lung & 0.12 \\
\hline Stomach & 0.12 \\
\hline Bladder & 0.05 \\
\hline Breast & 0.05 \\
\hline Liver & 0.05 \\
\hline Oesophagus & 0.05 \\
\hline Thyroid & 0.05 \\
\hline Skin & 0.01 \\
\hline Bone Surfaces & 0.01 \\
\hline Remainder & 0.05 \\
\hline
\end{tabular}


Table 3. List of biological effects from ICRP Pub. 60.

\begin{tabular}{|c|c|c|}
\hline Absorbed Dose [Gy] & Part & Biological Effect \\
\hline 0.15 & \multirow{2}{*}{ Gonand } & $\begin{array}{l}\text { Temporary } \\
\text { Sterilization }\end{array}$ \\
\hline 3.5 & & $\begin{array}{l}\text { Permanent } \\
\text { Sterilization }\end{array}$ \\
\hline 0.5 & $\begin{array}{c}\text { Bone } \\
\text { Marrow }\end{array}$ & $\begin{array}{l}\text { Disturbance of } \\
\text { Hematopoiesis }\end{array}$ \\
\hline Effective Dose [Sv] & \multicolumn{2}{|c|}{ Biological Effect } \\
\hline 0.1 & \multicolumn{2}{|c|}{$\begin{array}{c}\text { Mutation in } \\
\text { Chromosome Banding }\end{array}$} \\
\hline 0.5 & \multicolumn{2}{|c|}{ Lymphocytic } \\
\hline 1 & \multicolumn{2}{|c|}{$10 \%$ People } \\
\hline 3 & \multicolumn{2}{|c|}{$\begin{array}{c}\text { Dead in } 30 \text { - } 60 \text { Days } \\
\text { due to Injury to Bone Marrow }\end{array}$} \\
\hline 5 & \multicolumn{2}{|c|}{$\begin{array}{c}\text { Dead in } 10-20 \text { Days } \\
\text { due to Injury to GI Tract and }\end{array}$} \\
\hline 15 & \multicolumn{2}{|c|}{$\begin{array}{c}\text { Dead in 1- } 5 \text { Days } \\
\text { due to Injury to Nervous Systen }\end{array}$} \\
\hline
\end{tabular}

Table 4. List of fatality cancer incidences from ICRP Pub. 60.

\begin{tabular}{|c|c|}
\hline Organ or Tissue & $\begin{array}{c}\text { Fatality Cancer } \\
\text { Incidences }\left[\mathbf{1 0}^{-\mathbf{4}} \mathbf{S v}^{-\mathbf{1}}\right]\end{array}$ \\
\hline Bladder & 30 \\
\hline Bone Marrow (Red) & 50 \\
\hline Bone Surfaces & 5 \\
\hline Breast & 20 \\
\hline Colon & 85 \\
\hline Liver & 15 \\
\hline Lung & 85 \\
\hline Esophagus & 30 \\
\hline Stomach & 110 \\
\hline Thyroid & 8 \\
\hline Whole Rate & 500 \\
\hline
\end{tabular}

Table 5. List of general exposure considered in the system.

\begin{tabular}{|c|c|}
\hline General Exposure & Equivalent Dose $[\mathbf{m S v}]$ \\
\hline CT & 6.9 \\
\hline Chest Roentgenography & 0.05 \\
\hline PET & 2.2 \\
\hline Trip (Tokyo to NewYork) & 0.2 \\
\hline Background Radiation & 2.4 \\
\hline
\end{tabular}

\section{Demonstration}

The demonstration of the system is shown in Fig. 5. The small intestine around the left side of the body was irradiated for about 3 minutes under the conditions of having $10 \mathrm{GBq}$ of $\gamma$-rays emitted from the nozzle with $5^{\circ}$ beam divergence. Irradiated areas can be seen as small squares drawn around the small intestine on the target human body as shown in Fig. 6(A). The colour has changed from blue to red proportionally to the sum of the effective dose irradiated from each point. The equivalent dose for each organ or tissue on the body on the left is shown in Fig. 6(B). The learner can see the different damage sensitivity for each tissue. The name of the symptom caused by exceeding the dose threshold is shown in the Text Box on the area (C) in Fig. 6 with pointing the parts. Probabilistic effects are shown in the

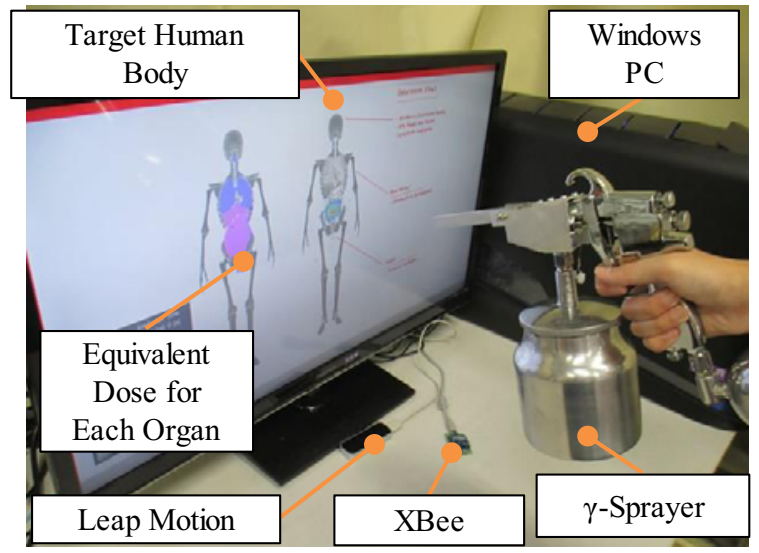

Fig. 5. The target of human body is being irradiated by using spray-type interface.

Text Box on the area (D) in Fig. 6. Learners can observe two kinds of effects of radiation in real time. Thus, learners can understand a basic concept of radiation protection. Comparison between the general exposures and the irradiated effective dose is shown in the Text Box on the area (E) in Fig. 6. Learners can have experience a quantitative feeling about the relationship between doses of general exposure and doses which cause the symptom intuitively. The irradiation conditions such as the radioactivity and the scale factor of the lapse time are changeable through a setting panel as shown in Fig. 6(F).

\section{Evaluation}

\subsection{Confirmation of the accuracy of the dose estimation}

Figure 7 and 8 illustrates the interpolated effective doses and the effective doses calculated by PHITS per incident $\gamma$-rays corresponding to each vertical angle $\theta$ and horizontal angle $\varphi$. A body around heart was aimed. Effective doses in $15^{\circ}, 45^{\circ}, 50^{\circ}, 65^{\circ}, 75^{\circ}, 105^{\circ}$ and $135^{\circ}$ were estimated based on response functions in real time. Effective doses are well-reproduced within the error of approximately $20 \%$.

Figure 9 is the images for equivalent dose to show the damage for each organ. Figure 9(A) shows the noninterpolated calculation. Figure 9(B), (C) and (D) are the images for $5 \mathrm{~cm}, 10 \mathrm{~cm}$, and $15 \mathrm{~cm}$ of each interval distance, respectively. Figure 10 shows the error of hue depending on interval distance in two irradiation points. The difference of hue contrast between the noninterpolated calculation and the interpolated calculation was over $20 \%$ more than $15 \mathrm{~cm}$ interval. Therefore, the interval was decided to be $10 \mathrm{~cm}$ in the system.

\subsection{Educational assessment}

The augmented $\gamma$-Spray system was assessed by questionnaire listed in Table 6. Pre-post questionnaire was taken for our 41 students in National Institute of Technology, Kagawa College. Their major is electronics and they hadn't taken any classes about radiological 


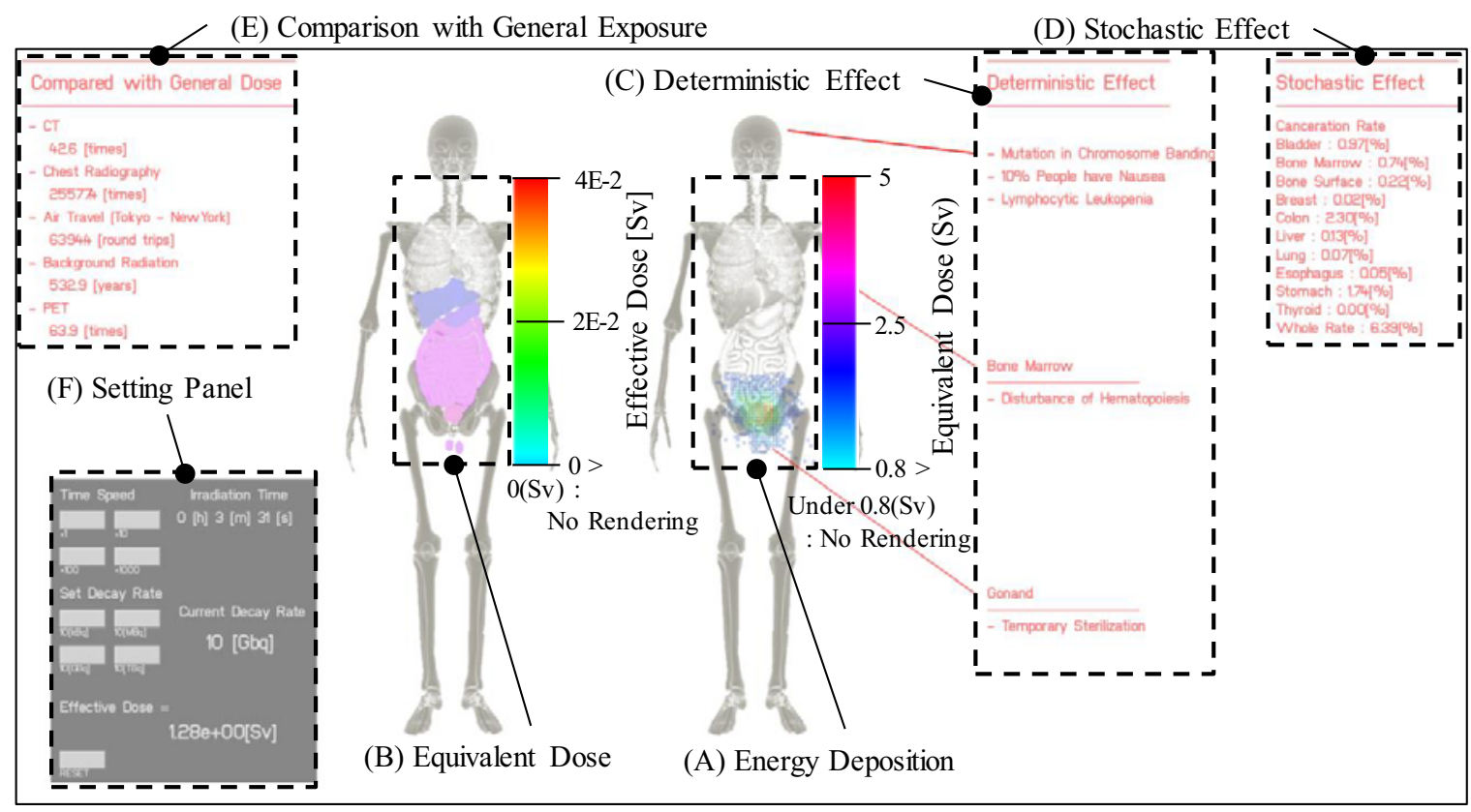

Fig. 6. Screenshot of projection images

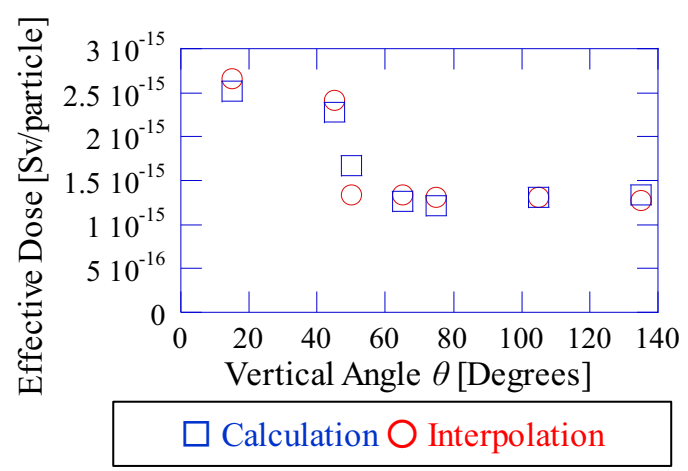

Fig. 7. Comparison of the calculated effective dose and the interpolated effective dose per unit $\gamma$-ray irradiated from each vertical angles.

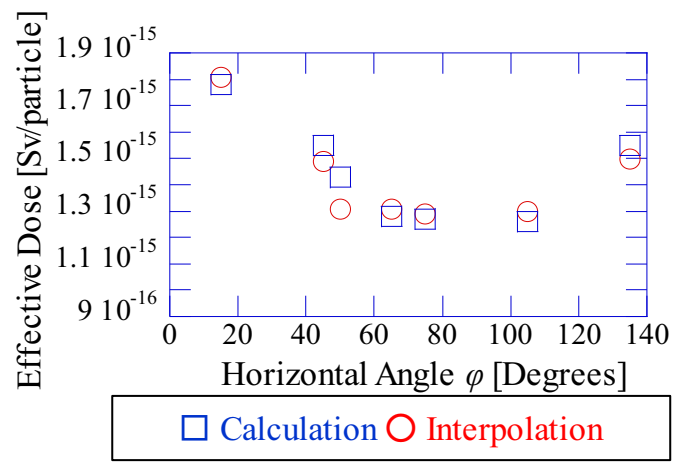

Fig. 8. Comparison of the calculated effective dose and the interpolated effective dose per unit $\gamma$-ray irradiated from each horizontal angles.

engineering or radiation medical physics. Questions of Q1 and Q5 were created learners' basic physical knowledge to protect from radiations. The aim of Q2, Q6, and Q7 was to survey basic understand the difference between definition of [Gy], [Bq], and [Sv]. Q3, Q4, Q8, and Q9 were created to assess basic comprehension about biological effects on human body. The augmented $\gamma$-Spray system can show the both effects in the monitor

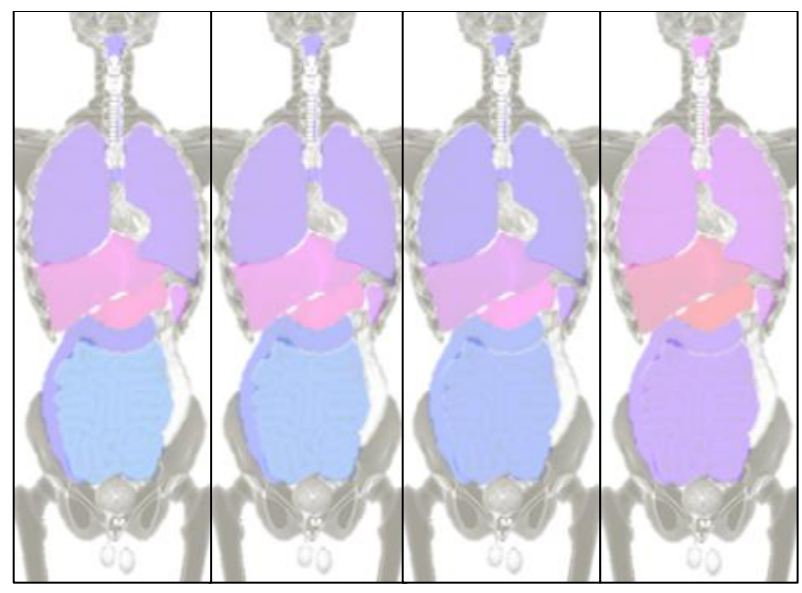
(A)Calculated
(B) $5[\mathrm{~cm}]$
(C) $10[\mathrm{~cm}]$
(D) $15[\mathrm{~cm}]$

value

Fig. 9. Visual evaluation of the equivalent dose depending on interval distance.

in real time. It's important to confirm learners' understand about the differences between deterministic effect and stochastic effect.

Figure 10 is a result of the questionnaire survey for the 41 learners. Figure 10 illustrates the changes of percentage of correct answer for both pre and post questionnaires. Before brief demonstration to explain how to use the augmented $\gamma$-Spray system, the learners were taken pre-questionnaire. After the pre-questionnaire, each learner touched the trigger of $\gamma$-Spray for about 5 minutes. We can see that the average percentage of the correct answer has grown up over $40 \%$ on the average after using the system. It was confirmed that the system has a capability of teaching the basic radiation protection concept, quantitative feeling of the radiation dose, and the biological effects. 
Table 6. Questionnaires for learners.

\begin{tabular}{|c|c|c|}
\hline No. & Question & Choice \\
\hline Q1 & $\begin{array}{l}\text { Are there any relationships } \\
\text { between the radiation damage and } \\
\text { irradiation time? }\end{array}$ & Yes, No \\
\hline Q2 & $\begin{array}{l}\text { Which unit means the activity of a } \\
\text { quantity of radioactive material in } \\
\text { which one nucleus decays per } \\
\text { second? }\end{array}$ & Bq, Sv, Gy \\
\hline Q3 & $\begin{array}{l}\text { How many times can you accept } \\
\text { when a doctor ask you to undergo } \\
\text { an X-ray inspection in one year? }\end{array}$ & $\begin{array}{l}\text { Zero, a few } \\
\text { times, more, } \\
\text { couple } \\
\text { dozen times }\end{array}$ \\
\hline Q4 & $\begin{array}{l}\text { Dose a radiation associated lesion } \\
\text { of agenesis, an hematopoiesis or } \\
\text { reduction of lymph have a } \\
\text { character that once the dose } \\
\text { threshold has been exceeded, the } \\
\text { severity of an effect increases } \\
\text { with dose? }\end{array}$ & Yes, No \\
\hline Q5 & A radiation intensity is changed by & $\begin{array}{l}\text { hardness of } \\
\text { a RI, } \\
\text { distance } \\
\text { from a RI , } \\
\text { temperature } \\
\text { of a RI }\end{array}$ \\
\hline Q6 & $\begin{array}{l}\text { Which unit means absorbed } \\
\text { energy per kilogram of the matter? }\end{array}$ & $\mathrm{Bq}, \mathrm{Sv}, \mathrm{Gy}$ \\
\hline Q7 & $\begin{array}{l}\text { Which unit indicates the equivalent } \\
\text { biological effect of the deposit of a } \\
\text { joule of radiation energy in a } \\
\text { kilogram of human tissue? }\end{array}$ & $\mathrm{Bq}, \mathrm{Sv}, \mathrm{Gy}$ \\
\hline Q8 & $\begin{array}{l}\text { Dose a probability of cancer } \\
\text { occurrence increases with } \\
\text { effective radiation dose? }\end{array}$ & Yes, No \\
\hline Q9 & $\begin{array}{l}\text { Are there any differences of } \\
\text { damage sensitivity between each } \\
\text { body organ for irradiations? }\end{array}$ & Yes, No \\
\hline
\end{tabular}

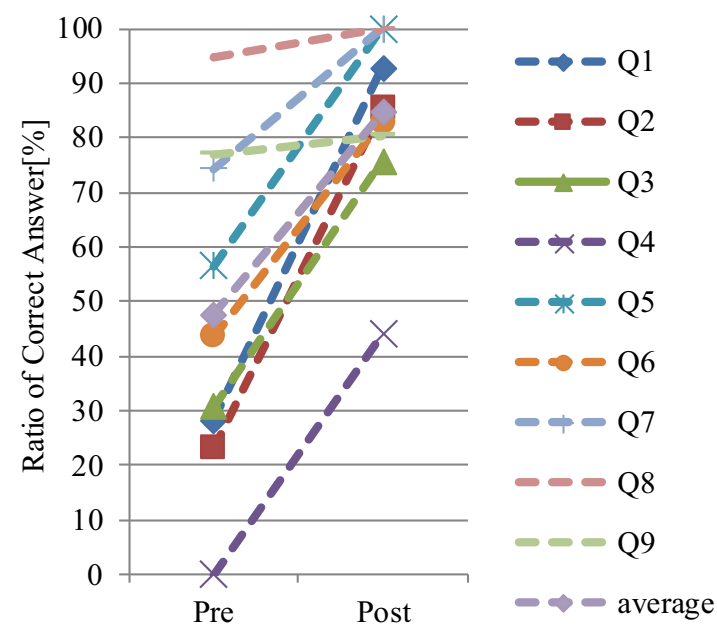

Fig. 10. Result of the questionnaire survey about teaching effectiveness of the system.

\section{Summary}

A new visualization system with a hand-held interface for education in radiation protection was proposed and demonstrated in this paper. The demonstration highlights some of the features used to help teach the concepts that the severity of radiation damage is related to exposure time and distance from the source and that different organs and tissues in the body have varying degrees of sensitivity to radiation. The learners can see radiation damage occurring in real time while the learner is pulling the trigger. Interpolation method was used to calculate equivalent dose in real time on each organ. The response functions for the method were calculated by using the PHITS Monte Carlo simulation code and a MIRD mathematical human phantom placed in a vacuum. It was confirmed that effective doses by interpolation method are well-reproduced within the error of approximately $20 \%$ at $10 \mathrm{~cm}$ interpolation interval. The augmented $\gamma$-Spray system was assessed by pre-post questionnaire for college students. The learners could understand a quantitative feeling about the relationship between the three units of radioactivity [Bq], absorbed dose [Gy], and effective dose [Sv]. It was also confirmed that the system has a capability of teaching the basic radiation protection concept, quantitative feeling of the radiation dose, and the biological effects.

\section{References}

1. J. Hudzietzová, J. Sabol, Int. J. Environ. Res. Public Health, 1, 132-139, (2014)

2. T. Sato et al., J. Nucl. Sci. Technol, 50, 913-923 (2013)

3. ICRP, ICRP Publication 74. Ann. ICRP 26 (3-4), 1533 (1996)

4. ICRP, ICRP Publication 60. Ann. ICRP 21 (1-3), 6153 (1991) 